\title{
Study of Weaning Practices among Mothers of Children less than One year of Age in Slum area of Multan \\ Shehla Qadir, ${ }^{1}$ Muhammad Kamran Adil, ${ }^{2}$ Uzma Arshad, ${ }^{1}$ Samina Badar ${ }^{1}$
}

\begin{abstract}
Background: Weaning is the key to the proper growth and development of a child. Mothers must do proper weaning practices in order to prevent malnutrition and infection in children.

Objective: To determine the weaning practice among mothers with infants aged 6 months to one year of age, and causes of delayed weaning.

Methodology: A cross-sectional descriptive study was carried out among the residents of the slum area of Jahangirabad, Multan, from 31st March to 25th May 2018. A close-ended questionnaire was used for collecting data from 85 mothers using non-probability convenient sampling technique. Frequency and percentages were calculated for qualitative variables like education, occupation, socio-economic status, the start of weaning time. Data were analyzed using SPSS version 20.

Results: Mothers who started weaning of their children at age of 6 months and above were $91 \%$. Mothers who felt their milk was enough for the baby were only $37 \%$. Mothers using marketed food for weaning were, $48 \%$. Illiterate mothers were, $45 \%$. Those who were doing weaning less than 6 times per day were $98 \%$. Families belonging to low socioeconomic status were, $61 \%$. On applying the chi-square test there was no significant association found between the start of weaning time and mother's education $(\mathrm{p}=0.3)$ or occupation $(\mathrm{p}=0.3)$.

Conclusion: A large proportion of children's population has started weaning above 6 months of age. There was no significant association found between the start of weaning time with the mother's education and occupation.

Key words: Weaning, Infants, Mother, Slum area, Practices.

Article Citation: Qadir S, Adil MK, Arshad U, Badar S, Study of Weaning Practices among Mothers of Children less than One year of Age in Slum area of Multan, JSZMC 2020;11(3):21-24. DOI: https://doi.org/10.47883/jszmc.v11i03.46
\end{abstract}

\section{Introduction}

According to WHO recommendation, weaning is the process by which a baby slowly gets used to eating adult foods and relies less on breast milk. ${ }^{1,2}$ Breast milk alone is not sufficient for the nutritional requirement of the child. It is deficient in vitamin A, Iron, and Zinc. ${ }^{3}$ Weaning is not a sudden withdrawal of breastfeeding. It is a gradual process of starting supplementary foods around the age of six months. The supplementary foods should be rich in protein and other essential materials. In our society, supplementary food materials are based on usually cow's milk, fruit juices, soft cooked rice, vegetables, Dhai, and suji. ${ }^{4,5}$ Weaning food should be rich in energy and micronutrients, free from contamination, without much salt or spices, easy to prepare from family foods, and cost-effective. ${ }^{4}$ The weaning period is the most crucial in child development. If weaning is not done properly, the child may suffer from malnutrition and infection. The weaning failure may bring other drastic conditions, like immunodeficiency, marasmus, and kwashiorkor, which are very fatal conditions. Weaning is the period of extensive mental alteration of both baby and parents. ${ }^{4,5}$ Babies become more attentive to the world around them and also become liberated in their day to day activities. Mothers at first spend their time completely with their babies, which during weaning alters. Mothers have to be dependent on their families to look-after after their young babies. Healthy growth and development don't include just correct feeding, it also includes emotional encouragement and the correct type of attention for the baby. Successful weaning includes all these points into consideration. Adequate knowledge of weaning foods and practices is an essential aspect of preventive pediatrics so as to improve child physical growth and development. ${ }^{5}$ Breast milk as only food was recommended up to the age of six months. ${ }^{6}$ The

1. Multan Medical and Dental College, Multan, Pakistan.

2. Children Medical Complex Multan, Pakistan.

Correspondence: Dr. Shehla Qadir, Multan Medical and Dental College, Multan, Pakistan. 
objective of this study was to determine the weaning practice among mothers with infants aged six months to one year, and the causes of delayed weaning.

\section{Methodology}

This descriptive cross-sectional study was conducted in urban slums of Multan city (Basti Jahangir Abad) from $31^{\text {st }}$ March to $25^{\text {th }}$ May 2018. This study was carried out after taking ethical approval from the hospital ethical committee. Mothers of children aged six months to one year were taken into study. Those mothers who were not willing to participate in the study were excluded further, the mothers who were having a sick child with some emergency condition were also excluded from the study. Out of the selected sample area, 85 mothers eligible for the study were drawn by non-probability convenient sampling technique. The data was collected through a preformed close-ended questionnaire. Frequency and percentages were calculated for qualitative variables like father education, mother education, mother occupation, socioeconomic status, the start of weaning time, reasons for delayed weaning, and giving marketed weaning foods. Chi-square test was applied to see the association between variables like the start of weaning time with mother's education and the start of weaning time with mother's occupation. Data were analyzed using SPSS version 20.

\section{Results}

This study was conducted to assess the weaning practices followed by the mothers in the urban slum area. Mothers who started weaning of their children at age of 6 months and above were, 91\%. Mothers who felt their milk was enough for the baby were, $37 \%$. Mothers using marketed food for weaning were $48 \%$. Regarding causes of delayed weaning, our study found that $36.5 \%$ of mothers think that milk is sufficient for baby, $17.6 \%$ think that baby cannot digest food, $19.4 \%$ delay weaning due to low socioeconomic status, $7.7 \%$ on family elders' pressure and $18.8 \%$ due to lack of knowledge. In this study, $91.8 \%$ of mothers gave their child weaning food less than 6 times per day, 3.5\% 6 times per day, and $4.7 \%$ more than 6 times per day. Illiterate mothers were, $45 \%$. Those who were doing weaning less than 6 times per day were, 98\%. Families belonging to low socioeconomic status were, $61 \%$. Among them, 65\% were housewives. The father's education was illiterate $38.9 \%$, primary $12.9 \%$, middle education $29.4 \%$, high school education $16.5 \%$, and graduate $2.4 \%$. In this study, $17.6 \%$ of mothers discontinued breastfeeding during weaning, while, $51 \%$ of mothers used only a homemade diet for weaning. On applying the chi-square test there was no significant association found between the start of weaning time and mother's education $(\mathrm{p}=0.3)$ or occupation $(\mathrm{p}=0.3)$. (Table I and II)

Table-I: Distribution of start of Weaning Time and Mother's Education

\begin{tabular}{|l|c|c|c|c|}
\hline Responses & $\begin{array}{l}\text { Lahore } \\
(\mathbf{n = 5 0})\end{array}$ & $\begin{array}{l}\text { Bahawalpur } \\
(\mathbf{n = 5 0 )}\end{array}$ & Total & P-value \\
\hline $\begin{array}{l}\text { Mother in Law knows } \\
\text { that a large family will } \\
\text { badly affect Daughter in } \\
\text { Law's health }\end{array}$ & $34(68 \%)$ & $33(66 \%)$ & $67(67 \%)$ & 0.4 \\
\hline $\begin{array}{l}\text { Mother in Law holds the } \\
\text { household budget }\end{array}$ & $29(58 \%)$ & $33(66 \%)$ & $62(62 \%)$ & 0.6 \\
\hline Sons favor mother & $15(30 \%)$ & $18(36 \%)$ & $66(66 \%)$ & 0.4 \\
\hline $\begin{array}{l}\text { Mother in Law wanted } \\
\text { more children }\end{array}$ & $34(68 \%)$ & $23(46 \%)$ & $57(57 \%)$ & 0.02 \\
\hline $\begin{array}{l}\text { More children will result } \\
\text { in poor child care }\end{array}$ & $33(66 \%)$ & $44(88 \%)$ & $77(77 \%)$ & 0.01 \\
\hline
\end{tabular}




\section{Discussion}

This study was carried out to assess the practices of mothers regarding the weaning of their babies in an underdeveloped urban slum area of Multan, Pakistan. Proper weaning is of prime importance for the adequate development of children as they face the risk of malnutrition and inadequate immunity against their increasing interaction with the environment. Improper and delayed weaning amplifies these risks and is a major contributor to the infliction of disease and stunted growth. ${ }^{6,7}$ WHO in collaboration with UNICEF developed the global breastfeeding collective to meet political, legal, financial, and public sustenance for breastfeeding. It has also developed strategies in order to guard, expand, and help adequate infant and young child feeding. There are multiple problems, mothers have to face regarding the weaning of their child, and out of these the most important one is the disinterest of the child in food. In such stances, parents should develop certain strategies to improve the interest of their child such as taking food in front of the child. This develops motivation in the child to eat similar food. ${ }^{8}$

In this study, only $9.4 \%$ of the mothers started weaning their children around the correct time of 6 months. This compared to the global data published by UNICEF in 2018, is at a marked difference from the rest of the country. ${ }^{7}$ According to UNICEF in 2012-13 nationally $66.3 \%$ of mothers started weaning around 6-8 months, while $81.6 \%$ and $59.7 \%$ of mothers from urban and rural settings started weaning around 6-8 months. According to UNICEF mothers divided into five socioeconomic categories from low to high started proper weaning in the following percentages; ${ }^{7} 37.8,49,70.9,85.5$, and 83.2, which resulted in $83.2 \%$ of mothers belonging to the top $20 \%$ socioeconomic status and $52 . \%$ in bottom 20\% socioeconomic status observing correct weaning age. UNICEF further reported that $81.2 \%$ of mothers with higher education practiced weaning at the proper time while 54.3\% of illiterate mothers practiced correct weaning time. This is in accordance with this study which observes that $61.2 \%$ of mothers belong to lower and $37.6 \%$ belong to lower-middle socioeconomic status and only $14.1 \%$ had higher education while more than $80 \%$ had less education or none. This compared with other countries' data by UNICEF shows that Argentina has one of the highest rates of proper weaning age at $96.6 \%$ while Somalia has one of the lowest at $15-17 \%$, whereas our neighbors China, India, Iran, and Afghanistan have $60 \%$, $45.8 \%, 75.9 \%$ and $61.0 \%$ rates, respectively. ${ }^{7}$

Nutritional Survey of Pakistan also indicates that the practices observed in this study are quite alarming by reporting that More than half $(51.3 \%)$ of the mothers interviewed across Pakistan reported they had started giving semisolid foods to their children at 6-8 months. ${ }^{8}$ The proportion was higher $(68.4 \%)$ in urban areas than in rural areas (44.7\%). KP (35.3\%) and AJK (35.7\%) had lower trends than other provinces. In comparison with a study conducted at the pediatrics OPD Ghurki Trust Hospital Lahore, 42\% of mothers started weaning at the correct age, $32 \%$ late and the rest early, ${ }^{9} 26 \%$ discontinued breastfeeding during weaning, while in this study $17.6 \%$ discontinued, and $44 \%$ reported that they used only homemade diet for weaning compared to $51 \%$ in this study.

Ashraf S et al reported that 29 out of 62 illiterate, 31 out of 53 primary schooled, 50 out of 70 high schooled, and 25 out of 33 Graduate mothers initiated weaning at the correct time thus highlighting the importance of educational awareness in this regard. ${ }^{10}$ A study carried out in rural Tumkur, India by Ananda et al, concluded that $18 \%$ of mothers delayed the weaning of their children, out of which $63 \%$ believed that milk was sufficient for the baby and $36 \%$ thought that the baby couldn't digest food. ${ }^{11}$ In comparison to this, regarding reasons for delayed weaning, our study found that $36.5 \%$ of mothers think that milk is sufficient for baby, $17.6 \%$ think that baby cannot digest food, $19.4 \%$ delay weaning due to low socioeconomic status, $7.7 \%$ on family elders' pressure and $18.8 \%$ due to lack of knowledge. In this study, $91.8 \%$ of mothers gave their child weaning food less than 6 times per day, $3.5 \% 6$ times per day, and $4.7 \%$ more than 6 times per day, whereas Ananda et al reported that $45.9 \%$ of mothers gave weaning food twice daily and $31 \%$ only once a day. In contrast to the $48.2 \%$ of mothers in this study giving marketed food to their children, only $13 \%$ of the mothers from Tumkur used marketed food. A cross-sectional study was conducted in the Urban Health Center of Govt. Medical College and hospital of Ambajogai, Maharashtra reported that $75.6 \%$ of mothers initiated weaning at the correct time of 6 months. ${ }^{12}$ Although the great majority of them were illiterate and the rest 
only primary schooler, it can be assumed that close proximity to a tertiary health care facility was the reason for their proper awareness regarding weaning practices.

\section{Conclusion}

Thus it is evident that the majority of the mothers of this area are carrying out poor practices regarding the weaning of their children, which poses a great danger to the children's proper development and growth. It is suggested that weaning should be started around the age of six months because the mother's milk is not sufficient for growth beyond six months. Weaning food material should be supplemented with proteins and other essential nutrients. If weaning is followed by diarrhea and growth failure, a nearby pediatrician should be consulted. Efforts should be made to design and promote the use of adequate homemade weaning foods.

Authors Contribution: SQ: Conception of work and Design of Work. MKA: Drafting and Revising. UA: Acquisition \& analysis SB: Analysis of data and drafting.

All the authors gave final approval for publication and agreed to be accountable for all aspect of work.

\section{Conflict of Interest: None Sources of Funding: Self}

\section{References}

1. WHO. Weaning from breast milk to family food. Geneva.pp.3. Available from: https://apps.who.int/ iris/handle/10665/39335

2. Mohammad ES, Ghazawy ER, Hassan EE. Knowledge, Attitude, and Practice of Breast Feeding \& Weaning Among Mothers of Children up to 2 Years old in a Rural Area in El- Minia Governorate, Egypt. J Family Med Prim Care. 2014; 3 (2): 136-140.
3. Kulsoom U, Saeed A: Breastfeeding practices and beliefs about weaning among mothers of infants age 0-12 months. J Park Med Assoc. 1997,47: 54-60.

4. Adhikari M, Kamal V, Karkee R, Gavidia T. Factors associated with early initiation of breastfeeding among Nepalese mothers: further analysis of Nepal Demographic and Health Survey, 2011. Int Breast feed J. 2014 Dec 5; 9(1):21.

5. Malathi V, Sivambika G, Lakshami L.A descriptive study to access the level of knowledge regarding weaning practice among mothers of under 5 children in Poonchari village, Kancheepuram District, India. International Journal of Scientific Research \& Education. 2017; 5(10).

6. Park K. Preventive Medicine in Obstetrics, Paediatrics, and Geriatrics. In: Bhanot BM, Publishers. Park Textbook of Preventive and Social Medicine. Jabalpur: 2018.pp.573.

7. United Nations Children's Fund, Division of Data Research and Policy (2018). Global UNICEF Global Databases: Infant and Young Child Feeding: Introduction to solids, semi-solids, and soft foods, New York, January 2018.

8. Bhutta ZA, Soofi SB, Habib MA, Hussain M, Lassi AR, Nawaz G, et al. National nutrition survey 2011 Pakistan. Planning Commission Planning and Development Division Government of Pakistan; 2011.p.82

9. Manzoor I, Daud S, Hashmi NR, Bukhari FSA, Munir MK, Sameer S, et al. Weaning; knowledge and practices. Professional Med J June 2009; 16(2):279-84.

10. Ashraf S, Ahmed M, Mushtaq MH, Singh G, Khan A. KAP survey in mothers towards infant care and feeding in Pakistan. Am J Epidemiol. 2017;1(1):001-7.

11. Kumar A, Rangaswamy KB, Kumar V. Weaning practices in rural Tumkur. Curr Pediatr Res. 2013;17(2):115-7.

12. Shaikh MR, Nagaonkar AS. A community-based study of breastfeeding and weaning practices among mothers in the urban field practice area of SRTR, GMC, Ambajogai. Int J Community Med Public Health. 2018 Jan;5(1):191-7 